\title{
ARTICLE
}

\section{Psychosocial interventions for dementia: from evidence to practice}

\author{
Bhamini Patel, Mark Perera, Jill Pendleton, Anna Richman \& Biswadeep Majumdar
}

Bhamini Patel is a CT3 trainee in old age psychiatry, Mersey Care NHS Trust. Mark Perera is an ST6 trainee in old age psychiatry, 5 Boroughs Partnership NHS Foundation Trust. Jill Pendleton is an advanced practitioner in dementia, Mersey Care NHS Trust. Anna Richman is a consultant old age psychiatrist, Mersey Care NHS Trust. Biswadeep Majumdar is a consultant old age psychiatrist, Mersey Care NHS Trust.

Correspondence Dr Bhamini

Patel, Waterloo Day Hospital, Park Road, Liverpool L22 3XR, UK. Email: Bhaminipatel@nhs.net

\begin{abstract}
SUMMARY
This article presents evidence for the efficacy of psychosocial interventions for people with dementia and their carers. The evidence base is not yet robust enough to clearly suggest which interventions are most suited for which environment. However, from our literature review there appears to be reason to use music therapy, aromatherapy, life story work, animal-assisted therapy and post-diagnosis/carer support work. We focus on both the traditional outcome measures of behavioural and psychological symptoms of dementia (BPSD) and the more difficult to measure, but equally important, person-centred outcomes of non-pharmacological interventions, as their properties are distinctly different from those of pharmacological agents.
\end{abstract}

\section{LEARNING OBJECTIVES}

- Be aware of the range of psychosocial interventions.

- Have a better understanding of the possible outcomes from given interventions.

- Be aware of the paradigm shift from managing BPSD to a person-centred approach that focuses on the patient's well-being and quality of life.

\section{DECLARATION OF INTEREST}

None.

This article is an update to the overview in Advances by Douglas et al (2004). We summarise the most well-researched psychosocial approaches for dementia by focusing on those with goodquality evidence, and acknowledge some of the newer and less-researched interventions listed in Box 1.

The recurrent theme throughout the literature regarding the efficacy of non-pharmacological interventions for dementia is the need for more robust evidence. Reasons for this include that research funding is largely targeted at biomedical approaches and that study designs are not always a good fit for the outcomes measured.

Kitwood (1997) proposed that a person-centred approach should be the bedrock for supporting people with dementia. The essential tenet is that personhood remains throughout the experience of dementia and it is the caregiver's responsibility to ensure that it is maintained. Person-centred practice recognises the underlying needs of the individual, often expressed through behaviour. The paradigm shift from 'managing' behavioural and psychological symptoms of dementia (BPSD) towards improving well-being, engagement and quality of life represents a significant change. These goals are more hopeful, leaving therapeutic nihilism in the past. Reducing antipsychotic prescribing (Banerjee 2009) presents another opportunity to exploit these approaches. A review of 26 non-pharmacological intervention categories concluded that non-pharmacological therapies are useful, versatile and potentially cost-effective in improving outcomes and quality of life (Olazarán 2010); however, they necessitate staff time, raising issues regarding priorities and risk (Lawrence 2012).

The essential component is the belief that distress and behaviour are expressions of unmet need - all behaviour having meaning - and are a response to the challenges dementia presents (Kitwood 1997). The key appears to be formulation or behavioural analysis (Moniz-Cook 2012) to understand the behaviour and its function for each person.

- Non-pharmacological approaches should be the first line of intervention (Douglas 2004; National Collaborating Centre for Mental Health 2007).

B0X 1 Psychosocial approaches for dementia that are in use but research is ongoing

- Cognitive retraining and cognitive rehabilitation

- Assistive technology (e.g. telecare, digital scrapbook, immersive space, intelligent lighting)

- Dementia training for carers

- Sonas (a multisensory stimulation technique)

- Play therapy

- Drama therapy/storytelling

- Meal positioning

- Therapeutic use of touch

- Occupational-based therapies 
- Non-pharmacological approaches provide opportunities to maintain personhood that traditional models lack in terms of meeting complex need.

- Classification of BPSD is complex, for example cognitive to sensorimotor activities, product to process (Perrin 2000) or the stepped care model (Brechin 2013).

- Interventions should be repositioned from managing BPSD to improving well-being.

Here, we have grouped the reviewed psychosocial interventions under the categories of creative, sensory, activity-based, psychological, carerfocused and environmental.

\section{Creative interventions}

These have developed significantly over the past 10 years as a means of engagement and expression for people with dementia. Described by Killick \& Allan (1999) as the 'undiminished possibility', they encourage participants and staff to see creativity as an opportunity for engagement not provided by other non-pharmacological approaches. Often outcomes are not classified in terms of BPSD as this term jars with the person-centred philosophy. The focus is on promoting well-being, quality of life and enrichment of experience, thereby improving mood and behaviour. Studies of creative arts-based approaches for dementia are mostly inadequate in terms of systematic study design, measurement tools and methods of analysis, and there is disagreement in terms of methodologies and evaluation (Beard 2012). However, a few adequately controlled evidence-based studies show favourable results for reducing BSPD.

\section{Art therapy}

Art therapy with people with dementia is distinct from art as therapy, as its basis is leisure (Killick 1999). The application of art therapy is varied. Drawing, painting and using arts media has therapeutic potential in itself without using it as a clinical therapy to stage dementia. Studies by Kahn-Denis (1997) and Rentz (2002) focus more on positive outcomes: across these studies 80 participants expressed pleasure and showed sustained attention and self-esteem. Ziesel's Arts for Alzheimer's programme (Zeisel 2009) demonstrated the potential that people living with dementia have to enjoy art appreciation.

\section{Life story work}

Life story work involves reviewing and evaluating a person's life events by working with them and their families, recording information and using it to help with care (Thompson 2011) (Box 2). Rooted

in the principles of reminiscence, maintaining communication and a sense of self, life story work has demonstrated significant growth over the past 10 years. McKeown et al's (2006) systematic review demonstrated a range of methodological approaches utilised to explore life story work, although studies largely focused on staff perceptions, with patient and carer experience less well explored. The reviewers concluded that life story work has 'far-reaching' benefits in health and social care, but that high-quality research is scarce.

Findings support life story work as enabling the person to make sense of their identity and to connect the past with the present (Oyebode 2008: pp. 151-167). Moos \& Bjorn (2006) report that life story work has a role in increasing self-esteem and quality of life, although they found diverse aims and methodologies.

This intervention is recognised as valuable, but it is complex and requires staff training (Beard 2012).

\section{Movement/dance therapy}

Beard (2012) reported that movement and dance studies demonstrated small changes in behavioural symptoms (e.g. reducing agitation), although the main focus was on increasing engagement with others. Dance and movement therapy provides opportunities for non-verbal communication, supporting speech and expression of thoughts, memories and emotions, and creative selfexpression (Dulicai 2005).

\section{Music therapy}

Music therapy has been used for a variety of conditions and patient groups (e.g. people with intellectual disability) and it is only in the past few

\section{BOX 2 Case study 1: Life story work}

$\mathrm{Mr} \mathrm{K}$ was a retired office manager, with a wife and two children, who had enjoyed a successful career and been a keen golfer. He was diagnosed with semantic dementia which soon led to complex problems at home. He had had input from speech and language therapists and occupational therapists to support him and his wife at home, which included developing a life story book. This detailed Mr K's life, his achievements, his special moments and his family and friends. He became extremely frustrated with his deficits in comprehension and expressive language and increasingly frequently he became upset and angry. Eventually, his wife felt unable to cope and the situation at home became untenable. He was admitted to the ward, a smart intelligent man unable to express his thoughts and feelings and unable to grasp what was being said. He was clearly distressed and angry, so his wife brought his life story book to the ward. This had a huge effect on the ward staff in helping them understand $\mathrm{Mr} \mathrm{K}$ and his behaviour. When people have few words, communication can be difficult and the life story book became a tool for engagement that gave $\mathrm{Mr} \mathrm{K}$ a sense of pride and visibly reduced his anxiety and stress. 
years that there have been more rigorous studies of its use with people with dementia. It is usually delivered in groups by a trained music therapist, and it makes use of the expressive elements of music (such as rhythm, melody and tone) to relate between the therapist and patients. Previous musical skills are not required to be able to engage in this therapy. Ueda et al (2013) reviewed the literature on the topic and concluded that music therapy had moderate effects on anxiety and smaller effects on behavioural symptoms; thus, they felt that there is evidence that this therapy is effective for BPSD.

\section{Sensory interventions}

\section{Light therapy}

Light therapy has shown mixed but promising results. The physiology of our internal biological clock responsible for our sleep/wake cycle is complex. This internal biological clock is situated in the suprachiasmatic nuclei of the hypothalamus. Although it is sensitive to social activities and meal times for its regulation, its strongest regulator is the light/dark cycle (Hanford 2013). It is known that with the progression of neurodegenerative dementias, sleep is disrupted; therefore maintaining the sleep/wake cycle is a biologically plausible intervention. The variation in the intensity of light used across studies as well as the timing were critical to the outcomes observed (Dowling 2005), and likely account for the differences in study results.

A Cochrane review of eight trials (Forbes 2009) revealed that there was inadequate evidence of the effectiveness of light therapy in managing cognition, sleep, function, behaviour or psychiatric disturbances associated with dementia, and that further studies of high methodological quality and further research are required. It is important to note that the review authors defined light therapy as 'any intensity and duration'. In fact, a study by Barrick et al (2010) showed that agitation was actually higher under high-intensity bright morning light.

Burns et al (2007) showed that after 2 weeks of light therapy at $10000 \mathrm{lux}$ from $10.00 \mathrm{~h}$ to $12.00 \mathrm{~h}$ there were improvements in the Cohen-Mansfield Agitation Inventory (CMAI; Cohen-Mansfield 1986), and it is suggested that individuals with higher initial CMAI scores may benefit the most from light therapy. More recently, Hanford $\&$ Figuero (2013) published a review of 17 studies on the effects of light therapy on sleep, agitation and mood. Regarding sleep, the authors found that exposure to bright light at $>1000$ lux at the cornea improved night-time sleep, increased daytime wakefulness and reduced agitated behaviour in the evening.

Figueiro (2008) proposes a 24-hour lighting scheme that can positively affect sleep, mood and agitation as well as reduce the risk of falls.

\section{Aromatherapy}

Aromatherapy is a complementary therapy that involves the use of essential oils (mainly Melissa balm and lavender) applied directly to the skin, heated in a burner or placed in a bath. It is thought to work mainly by providing sensory stimulation and the variety of application methods means it can be used in different settings. Fung et al (2012) concluded that their review of 11 randomised controlled studies showed evidence in favour of the use of aromatherapy for BPSD as well as improvement in cognition and quality of life, but also noted reports of adverse effects.

\section{Multisensory approaches}

Rooms specifically designed to achieve 'sensoristasis' are thought to reduce agitated behaviours. Sensoristasis, which has been in use since the 1970s, is a balance between being over- and under-stimulated (Sanchez 2013). A specialised multisensory room may contain items such as coloured lights, water columns and aromatherapy.

Sanchez et al (2013) carried out a review to determine the efficacy of this approach in dementia. They reviewed papers from 1990 to 2012 and although 63 studies were found, only 18 fulfilled their inclusion criteria. They looked at the outcomes of behaviour, mood, cognitive level and communication/interaction. With respect to behaviour there are conflicting results; some studies show a decrease in agitation, some find no significant difference. Interestingly, one study in which multisensory approaches were integrated into daily care showed that improvements in certain aspects of behaviour, such as apathy and aggression, were maintained 15 months after the new regime had been introduced. Integration of the approach into the daily care routine also showed a significant improvement in mood. It seems that the use of multisensory approaches in early dementia improves scores on the Mini-Mental State Examination (MMSE; Folstein 1975), although the outcome of cognition has not been studied extensively. On the outcome of verbal and nonverbal communication it seems that the integrated approach produced significant improvements. The long-term effectiveness of these approaches needs to be studied in further trials. 


\section{Animal-assisted therapy}

Animal-assisted therapy covers any form of therapy that involves animals. For people with dementia it usually means hands-on interaction with a domesticated pet brought into the care setting by a trained handler. It is thought to work partly through sensory stimulation, but can also help trigger positive memories and improve social interaction. Bernabei et al's 2013 review noted that there were improvements on levels of agitation and quality of social interaction, but studies looking at the effects on cognition and mood were lacking.

\section{Activity-based interventions}

\section{Exercise}

Physical exercise features prominently in terms of primary prevention of dementia in reducing vascular risk. Exercise appears to have a neuroprotective function, increasing hippocampal volume, although the direct effect on cognition is still unclear; there are obvious benefits for quality of life, physical health and affective symptoms.

Forbes et al (2008) state that there is more conclusive evidence regarding aerobic exercise, with National Institute for Health and Care Excellence (NICE) guidance (National Institute for Health and Clinical Excellence 2008) recommending $30 \mathrm{~min}$ of aerobic exercise five times a week. Extrapolation from studies with healthy older people and animals is difficult owing to methodological issues, but the potential of physical exercise to ameliorate the symptoms of dementia is interesting.

Buchman and colleagues (2012) concluded that higher levels of daily activity are associated with a reduced rate of Alzheimer's disease, and Winchester et al (2012) found that for a group of people with early Alzheimer's disease, walking for over $2 \mathrm{~h}$ a week for 1 year led to a significant increase in MMSE score over the control group. Studies have demonstrated improved cognitive functions, executive function (Baker 2010), attention and information processing (Lautenschlager 2008; Vreugdenhil 2012) and improved physical health (Heyn 2004).

\section{Other activity-based approaches}

Occupation is described by Kitwood (1997) as one of the main psychological needs of people with dementia and by Perrin (1997) as the severest loss in dementia. Lack of occupation leads to sensory deprivation, boredom, isolation and low mood (Brechin 2013). Activity covers a diverse range of interventions, and studies have looked at particular

activities. The appropriate use of activity becomes the essential component, matching activity with the abilities of the person to engage in something which gives them meaning. Brooker and colleagues (2007) developed an activity-based project to look at enrichment opportunities founded on the assumption that people with dementia are able and entitled to enjoy life. They acknowledge that the evidence was weak but the observable signs were undeniable (Beard 2012) in terms of a sense of connection, well-being, belonging, self-autonomy and identity.

\section{Psychological interventions}

\section{Doll therapy}

James et al (2006) and Verity (2006) have provided demonstrable efficacy for the use of dolls as therapy for people with dementia. Although not well understood in terms of theoretical base, it has grown from the work of Bowlby and attachment theory (Bowlby 1960) and links the way people with dementia experience the world (as unfamiliar and unsafe) to heightening their need for attachment (frequently attaching themselves to staff members, other residents or objects) (Box 3). Meissen's (1993) work has also been integrated to produce a rationale for the use of dolls as therapy.

It was the Newcastle Challenging Behaviour Service that delivered the first empirical studies of

BOX 3 Case study 2: doll therapy

$\mathrm{Mr} \mathrm{A}$ was a resident in a nursing home, with dementia and complex needs as well as loss of communication skills. As a result he was becoming very distressed and for long periods would pace up and down the corridors, getting involved in angry exchanges with other people. One of the other people in the home was using a doll and finding comfort in doing so. Unexpectedly, one day Mr A found the doll and started to walk around the home with it, talking to and cradling it. He appeared to find great comfort in the doll and it became his constant companion. One evening staff found him sleeping on the edge of his bed where he had made a cradle from his blankets for the doll. The doll met some need within him that was not satisfied by other interventions or by prescribed pharmacological agents: he was relaxed, showed pleasure and his periods of distress abated. It was not anticipated by any of the staff that this man would even contemplate having a doll, yet he chose it himself and was reassured by the connection he formed.

In this case the unsettled and agitated behaviour can be an expression of unmet psychological need. Kitwood (1997) states that these unmet needs are often the need for attachment, comfort, inclusion, love, identity and occupation. Mr A's unsettled behaviour might have a result of any of these needs being unmet. Doll therapy is an attempt to meet these needs.

As it is difficult to assess how people will respond to dolls, there are guidelines (James 2006) about their use which should always be considered before implementation. The doll should be available for the person to engage with themselves rather than given to the person when they do not react well. In addition, if doll therapy is identified as a possible intervention, its purpose should always be explained to the family first. 
doll therapy in dementia in 2006. They found that people who used dolls appeared less anxious, more active and more content (James 2006). Mackenzie et al (2006) and Ellingford et al (2007) showed similar results, indicating that there is a place for doll therapy in dementia care. However, Stevenson and colleagues (2010) stressed the need for caution as not all people respond well to it. Following their earlier work, Mackenzie and colleagues (2007) developed guidelines for using dolls with people with dementia because of the ethical issues associated with it.

\section{Reminiscence therapy}

Reminiscence therapy usually takes place in a group setting and makes use of photographs, music or video recordings and other objects to trigger personal memories. It has been used in the treatment of other disorders, such as depression. Douglas et al (2004) noted the paucity of high-quality studies, but in 2007 a multicentre, pragmatic randomised controlled trial (REMCARE) set out to examine the effectiveness and cost-effectiveness of reminiscence therapy against treatment as usual (Woods 2012). Unfortunately, the authors of the study concluded that reminiscence therapy was not an effective intervention in terms of quality of life or psychological distress for caregivers and was possibly worse for the latter outcome. They reported that those who continued with the study as planned to 3 months and 10 months showed some improvement in autobiographical memory, but this was accompanied by their caregivers reporting greater levels of stress.

\section{Cognitive stimulation therapy}

Cognitive stimulation therapy is a group therapy which aims to stimulate and engage patients with mild to moderate dementia. Each session follows a general theme or activity chosen from a list by the group, such as physical games, being creative and current affairs. It was developed following a review of reality orientation therapy (Spector 2000) and was recommended in the NICE guidelines for dementia (National Collaborating Centre for Mental Health 2007). A systematic review by Aguirre and colleagues (2013) showed significant improvements in cognition and quality of life, but not on other specific measures of BPSD. They also acknowledged that there was currently a lack of evidence for the long-term effects of cognitive stimulation therapy.

\section{Validation therapy}

This therapy is based on the idea that in accepting the reality and personal truth of another's
BOX 4 Example of validation

Patient: 'Where is my coat? It's raining out there and I need to be leaving soon.'

Staff: 'Your coat... Um... Not sure Henry. Come on, we'll go and look for it.'

Patient: 'Lots to do today, you know. Have to get my hair cut, pick up the kids...'

Staff: 'Right, well, you do have a lot to do... It seems you like to run around and keep busy.'

Patient: 'I always have done. Don't like to sit around, you know.

experience we may be able to better communicate with them and reduce their distress (Box 4). Developed between 1963 and 1980 by Naomi Feil - a social worker and author of two books ( The Feil Method (Feil 1982) and Validation Breakthrough (Feil 1993)) - the aim of the approach was to remedy what she felt was lacking in reality orientation. Its principles are not unique and are shared by other person-centred approaches:

- all people are valuable, no matter how disoriented they are;

- painful feelings that are expressed, acknowledged and validated by a trusted listener will diminish.

- Painful feelings that are ignored or suppressed will gain strength (Feil 1993).

Validation therapy has at its centre 14 techniques including (but not limited to) the use of nonthreatening factual words to build trust - 'who', 'what', 'where', 'when' and 'how', but not 'why' rephrasing the person's speech to them, taking advantage of ambiguity such as using 'they', 'he', 'she' or 'it' to respond to their conversation and using a clear, low, loving tone of voice (Feil 1993).

In a Cochrane review, Neal et al (2003) concluded that, owing to the limited number of trials and the small numbers of participants, there was insufficient evidence to allow firm conclusions about the efficacy of validation therapy on the outcomes of behaviour, cognition, mood and activities of daily living for people with dementia.

In their 2009 update, Neal et al carried out a further search to review any new studies, only finding one study, which was later deemed not suitable as the intervention included reminiscence therapy as well as validation therapy. We cannot locate any further studies on validation therapy. The challenges for research are in determining the components of validation that are effective for given outcomes, which should include the difficultto-measure outcomes of well-being and quality of 
BOX 5 What psychiatrists can do to promote psychosocial interventions

Psychosocial interventions are difficult to implement, for both cultural and economic reasons (Lawrence 2012), but our opinion, psychiatrists can take a number of steps to promote them:

- keep abreast of the literature, thereby developing a sense of the challenges and directions being taken in this field

- have frank discussions with staff at care homes regarding the practicalities (benefits and difficulties) of introducing, for example, music therapy for residents

- engage with local organisations that deliver life story work and animal-assisted therapy

- carry out an interventional study to measure behavioural changes before and after introduction of a psychosocial intervention, providing a unique insight into what appears to work for the patients and staff in their care

- set up a post-diagnostic support group for their patients and carers; nursing and support staff would run the group, but the treating psychiatrist would actively oversee and modify it

life, which so far have not been included. In this way, the evidence-based components of validation therapy might successfully be incorporated into other therapies (Neal 2003). Common to all psychosocial interventions, we must then deal with the challenges of their implementation into clinical practice (Box 5).

\section{Cognitive training}

Cognitive training - involving guided practice on a set of tasks and cognitive rehabilitation, individualised techniques or compensatory strategies - is designed to assist memory impairment and other cognitive difficulties. Clare $\&$ Woods' review in 2003 demonstrated no significant benefits from cognitive training, stating that it was impossible to draw any conclusions as study quality was limited. A more recent review (Baher-Fuchs 2013) aimed to evaluate efficacy of these interventions with people with mild Alzheimer's disease or vascular dementia. The authors evaluated 11 randomised controlled trials and found that cognitive training was not associated with positive or negative effects with reference to the outcomes and, again, methodological quality was low to moderate. The authors concluded that evidence is limited, with no significant benefits of cognitive training, acknowledging the lack of adequate measurement tools to capture benefits. Only one randomised controlled trial of cognitive rehabilitation (Clare
2010) was found by the authors of the review, but this did show 'promising' results in self-reported measures of goal performance in the short term.

A systematic review by Gates and colleagues (2011) concluded that cognitive exercises could produce moderate to large improvements in memory outcomes. However, this training was for adults with mild cognitive impairment 'at risk of developing dementia', and reliability is unclear owing to the quality of the trials and lack of statistical synthesis. The authors highlight the need for more robust studies.

\section{Carer-focused interventions}

The range of behaviours encompassed by BPSD (Box 6) (as opposed to cognitive decline or physical dependence on others) has been found to impose the greatest burden on caregivers and predict their decision to seek residential or nursing care for a family member with dementia (Brodaty 2012). Caregivers could therefore be an effective medium for delivering interventions to minimise these symptoms.

\section{Interventions in the community}

Brodaty \& Arasaratnam (2012) carried out a metaanalysis of the effectiveness of family caregiver interventions on the management of BPSD in people living in the community. Twenty-three studies (of which 16 were randomised controlled trials) showed largely positive or partially positive results. Interventions included education for caregivers (e.g. planning for emergencies, legal and financial issues), activity planning and environmental design, enhancing support for caregivers (e.g. internet or telephone support), self-care techniques for caregivers (e.g. music therapy, stress management) and exercise. The effects were noted to be at least comparable to those of antipsychotics. The authors concluded that successful interventions involved 9-12 home sessions tailored to the needs of the person with dementia and the caregiver, delivered over 3-6 months, interspersed with telephone sessions and subsequent individual or group telephone

\section{BOX 6 Behavioural and psychological} symptoms of dementia (BPSD)

\begin{tabular}{ll}
\hline - Depression & - Pacing \\
- Anxiety & - Wandering \\
- Apathy/Indifference & - Agitation \\
- Delusions & - Disinhibition \\
- Hallucinations & - Euphoria
\end{tabular}


follow-ups. The meta-analysis does not answer questions about the optimal duration, frequency and setting of interventions at a practical level. These will be defined questions for future research.

\section{Post-diagnostic support}

The National Dementia Strategy (Department of Health 2009) identifies the need for good-quality, structured support after diagnosis. There are various models of post-diagnostic support for carers, but most are psychoeducational in nature, providing support for $6-8$ sessions. Research by Whitlatch and colleagues (2005) demonstrate that people in the early stages of dementia are often as aware of the practical implications and problems as caregivers. Robinson et al (2005) suggest that a support group for the person and their potential carer may provide the greatest benefit for both parties.

A systematic review by Marim and colleagues (2013), including seven randomised clinical

BOX 7 Measuring outcomes in psychosocial interventions research: the hurdles

Psychosocial interventions do not lend themselves well to the gold standard randomised controlled efficacy trials used for pharmacological interventions. In addition to reviewing the findings from two health technology assessments on non-pharmacological interventions for dementia in Germany (German Institute for Quality and Efficacy in Health Care 2009; Rieckmann 2009), Schwarzbach et al (2012) provide an insightful and extremely clear analysis of the methodological problems encountered by research into nonpharmacological interventions, as well as providing some suggestions for ongoing research.

\section{Inclusion criteria}

Studies use different tools to make a diagnosis - how comparable then are the studies?

\section{Interventions themselves}

Interventions with the same name may, in practice, be applied very differently, so treatments even with the same name cannot always be compared. Some treatments may have been applied as a major departure from the usual delivery of care; others with the same name may have been used for only a set number of sessions. Again, comparison is not ideal, but does occur in practice, obscuring true results.

\section{Sample size and study duration}

Very few studies in Schwarzbach et al's review had more than 200 patients; the duration of studies ranged from $1 \mathrm{~h}$ to 52 weeks (they do not report an average).

\section{Comparators}

Many studies do not define 'standard care', which will be different across studies. Furthermore, staff's awareness that a study is being carried out may mean that patients in the standard care arm receive a change in their usual care as staff increase their engagement with them.

Even if there is a good degree of matching for patients taking medication, one might argue that it may reduce the patient's ability to derive benefit from psychosocial interventions or that it may be harder for a psychosocial intervention to show an additional benefit.

\section{Clinical end-points (outcomes} In pharmacological research clinical endpoints are requested by drug authorisation agencies. In non-pharmacological research, there is currently little guidance and studies may be using non-validated questionnaires, leading to problems in interpretation of the outcomes the produce.

Schwarzbach et al remind us that the lack of evidence should not imply lack of efficacy. studies, showed that educational and support programmes for caregivers reduced caregiver burden when compared with standard care.

\section{Environmental interventions}

Lawton (1990) recognised the role of the environment, acknowledging the vital nature of designing environments to meet the needs of people with dementia, but describing the challenges in terms of robust research design to measure efficacy and impact on quality of life. Zeisel et al (2003) demonstrated an association between behaviour and environmental design features, describing the potential the environment has for contributing to improvements in the symptoms of dementia by being comforting, safe and understandable. The physical environment can help people with dementia achieve their potential, avoid increased disability and enrich life quality (Davis 2009). Although the physical environment is important, so too is the psychosocial environment, preserving personhood, reducing the need for antipsychotic medication and improving quality of life (Werezak 2003).

The principles of dementia-friendly environments are now widely recognised. Bicket and colleagues (2010) indicated that the physical environment in assisted-living facilities probably affects neuropsychiatric symptoms and quality of life. Parker et al (2004) recommend that there should be a balance between choice and control, physical support, normalness and authenticity, comfort, cognitive support and personalisation as these are all associated with increased quality of life. Privacy reduces aggression and agitation and improves sleep (Morgan 2004).

\section{Measuring outcomes of psychosocial interventions}

A commentary by Kolanowski \& Hill (2013) on the Brodaty et al meta-analysis raises worthwhile points. Kolanowski \& Hill report that the meta-analysis followed the PRISMA (Preferred Reporting Items for Systematic Reviews and Meta-Analysis) statement guidelines (with a few exceptions), increasing confidence in the validity of their results. These guidelines help authors improve the quality of their reporting for studies of this type. Kolanowski \& Hill feel that current measures of BPSD lack precision, meaning that they might not pick up on a change in outcome. They also reiterate that quality-of-life indicators may be better measures and this appears to be an emerging theme that we have noted. Kolanowski $\&$ Hill also report that reliance on randomised controlled trials as the sole source of evidence 


\section{B0X 8 Useful resources}

Alzheimer's Society (for information about local groups) (www.alzheimers.org.uk)

Cognitive stimulation therapy (www.cstdementia.com)

INTERDEM (www.interdem.org)

Life Story Network (www.lifestorynetwork.org.uk)

excludes much available data; this is not the first time that the idea of the randomised controlled trial not being the gold standard in measurement of this particular type of outcome has been proposed (Box 7).

\section{Conclusions}

As demonstrated, the psychosocial interventions for dementia are vast. They range from those that are utilised in practice (with little or no evidence base) to those that are being studied to develop an evidence base, on which more widespread implementation may follow.

INTERDEM (early detection and timely INTERvention in DEMentia) was established in 1999 to spearhead robust research into timely dementia care interventions (Box 8). There is also work into the efficacy of psychosocial interventions in mild cognitive impairment, although this would be beyond the scope of this article and has not been reviewed. Music therapy, life story work, multisensory approaches, light therapy, cognitive stimulation therapy, doll therapy and exercise show promising preliminary results.

Ongoing research must take into account the difficulties posed by intervention heterogeneity and measuring clinical end-points (outcomes). We hypothesise that in adopting a person-centred approach, symptoms conceptualised as BPSD may indeed diminish, in addition to the benefits of improved quality of life and well-being for patients. For those studies that have shown no benefit, researchers must ensure studies are replicated with an improvement in intervention heterogeneity and measurement of clinical end-points. We encourage sustained clinical interest and research in this lateralised approach to dementia care to add to the tools at our disposal for comprehensive dementia management. Carrying out high-quality research into non-pharmacological interventions presents different challenges to those of a pharmacological agent. To improve dementia care for the 800000 patients currently living with dementia in the UK, as well as for their carers, researchers, clinicians and health policy makers must collaborate and embrace this challenge.

\section{References}

Aguirre E, Woods R, Spector A, et al (2013) Cognitive stimulation for dementia: a systematic review of the evidence of effectiveness from randomised controlled trials. Ageing Research Reviews, 12: 253-62.

Baher-Fuchs A, Clare L, Woods B (2013) Cognitive training and cognitive rehabilitation for mild to moderate Alzheimer's disease and vascular dementia. Cochrane Database of Systematic Reviews, 6: CD003260.

Baker L, Frank L, Foster-Schubert K, et al (2010) Effects of aerobic exercise on mild cognitive impairment. Archives of Neurology, 67: 71-9. Banerjee S (2009) The Use of Antipsychotic Medication for People with Dementia: Time for Action (A Report for the Minister of State for Care Services). Department of Health.

Barrick A, Sloane P, Williams C, et al (2010) Impact of ambient bright light on agitation in dementia. International Journal of Geriatric Psychiatry, 25: 1013-21.

Beard RL (2012) Art therapies and dementia care: a systematic review. Dementia, 11: 633-56.

Bernabei V, De Ronchi D, La Ferla T, et al (2013) Animal-assisted interventions for elderly patients affected by dementia or psychiatric disorders: a review. Journal of Psychiatric Research, 47: 762-73.

Bicket M, Samus 0, McNabney M, et al (2010) The physical environment influences neuropsychiatric symptoms and other outcomes in assisted living residents. International Journal of Geriatric Psychiatry, 25: 1044-54.

Bowlby J (1960) Attachment and Loss, Vol. 1. Attachment. Hogarth Press.

Brechin D, Murphy G, James I, et al (2013) Alternatives to Antipsychotic Medication: Psychological Approaches in Managing Psychological and Behavioural Distress in Dementia (Briefing Paper for the British Psychological Society). BPS.

Brodaty H, Arasaratnam C (2012) Meta-analysis of nonpharmacological interventions for neuropsychiatric symptoms of dementia. American Journal of Psychiatry, 169: 946-53.

Brooker D, Woolley R, Lee D (2007) Enriching opportunities for people living with dementia in nursing homes: an evaluation of a multi-level activity-based model of care. Aging and Mental Health, 11: 361-70.

Buchman A, Boyle P, Yu L, et al (2012) Total daily physical activity and the risk of Alzheimer's disease and cognitive decline in older adults. Neurology, 78: 1323-9.

Burns A, Allen H, Tomenson B, et al (2007) Bright light therapy for agitation in dementia: a randomized controlled trial. International Psychogeriatrics, 21: 711

Clare L, Woods B (2003) Cognitive rehabilitation and cognitive training for early stage Alzheimer's disease and vascular dementia. Cochrane Database of Systematic Reviews, 4: CD003260

Clare L, Linden D, Woods RT, et al (2010) Goal-oriented cognitive rehabilitation for people with early-stage Alzheimer disease: a singleblind randomized controlled trial of clinical efficacy. American Journal of Geriatric Psychiatry, 18: 928-39.

Cohen-Mansfield J (1986) Agitated behaviors in the elderly. II. Preliminary results in the cognitively deteriorated. Journal of the American Geriatrics Society, 34: 722-7.

Davis S, Byers S, Nay R, et al (2009) Guiding design of dementia friendly environments in residential care settings: considering the living experiences. Dementia, 8: 185-203.

Department of Health (2009) Living Well with Dementia: A National Dementia Strategy. Department of Health.

Douglas S, James I, Ballard C (2004) Non-pharmacological interventions in dementia. Advances in Psychiatric Treatment, 10: 171-7.

Dowling G, Hubbard E, Mastick J, et al (2005) Effect of morning bright light treatment for rest-activity disruption in institutionalized patients with severe Alzheimer's disease. International Psychogeriatrics, 17: 221-36

Dulicai D, Berger M (2005) Global dance/movement therapy growth and development. The Arts in Psychotherapy, 32: 205-16. 


\section{MCQ answers \\ $1 \mathrm{c} \quad 2 \mathrm{~d} \quad 3 \mathrm{~b} \quad 4$ a $\quad 5 \mathrm{e}$}

Ellingford J, Mackenzie L, Marsland L (2007) Using dolls to alter behaviour in patients with dementia. Nursing Times, 103: 36-7.

Feil N (1982) The Feil Method: How to Help Disoriented Old-Old. Feil Productions.

Feil N (1993) The Validation Breakthrough: Simple Techniques for Communicating with People with 'Alzheimer's-Type Dementia'. Health Promotion Press.

Figueiro MG (2008) A proposed $24 \mathrm{~h}$ lighting scheme for older adults. Lighting Research and Technology, 40: 153-60.

Folstein MF, Folstein SE, McHugh PR (1975) 'Mini-mental state'. A practical method for grading the cognitive state of patients for the clinician. Journal of Psychiatric Research, 12: 189-98.

Forbes D, Forbes S, Morgan D, et al (2008) Physical activity programme for people with dementia. Cochrane Database of Systematic Reviews, 3: CD006489.

Forbes D, Culum I, Lischka A, et al (2009) Light therapy for managing cognitive, sleep, functional, behavioural or psychiatric disturbances in dementia. Cochrane Database of Systematic Reviews, 4: CD003946.

Fung J, Tsang H, Chung R (2012) A systematic review of the use of aromatherapy in treatment of behavioral problems in dementia. Geriatrics and Gerontology International, 12: 372-82.

Gates N, Sachdev P, Fiatarone Singh M, et al (2011) Cognitive and memory training in adults at risk of dementia; a systematic review. $B M C$ Geriatrics, 11: 55

German Institute for Quality and Efficiency in Health Care (2009) Nichtmedikamentöse Behandlung der Alzheimer Demenz (IOWiGBerichte Nr. 41) [Non-Pharmacological Treatment of Alzheimer's Dementia (IDWiG Reports no. 41)]. Institut für Qualität und Wirtschaftlichkeit im Gesundheitswesen.

Hanford N, Figuero M (2013) Light therapy and alzheimer's disease and related dementia: past, present and future. Journal of Alzheimer's Disease, 33: 913-22

Heyn P, Abreu BC, Ottenbacher KJ (2004) The effects of exercise training on elderly persons with cognitive impairment and dementia: a metaanalysis. Archives of Physical Medicine and Rehabilitation, 85: 1694-704.

James I, Mackenzie L, Mukaetova-Ladinska E (2006) Doll use in care homes for people with dementia. International Journal of Geriatric Psychiatry, 21: 1093-8.

Kahn-Denis K (1997) Art therapy with geriatric dementia clients. Art Therapy, 14: 194-9.

Killick J, Allan K (1999) The arts in dementia care: tapping a rich resource. Journal of Dementia Care, 7: 35-8.

Kitwood T (1997) Dementia Reconsidered: The Person Comes First. Open University Press.

Kolanowski A, Hill N (2013) Community-based non-pharmacological interventions delivered by family caregivers reduce behavioural and psychological symptoms of dementia. Evidence Based Nursing, 16: 67-8.

Lautenschlager N, Cox K, Flicker L (2008) Physical activity improves cognitive function in people with memory impairments. JAMA, 300: 1027-37.

Lawrence V, Fossey J, Ballard C, et al (2012) Improving quality of life for people with dementia in care homes: making psychosocial interventions work. British Journal of Psychiatry, 201: 344-51.

Lawton M (1990) Environmental approaches to research and treatment of Alzheimer's disease. In Alzheimer's Disease Treatment and Family Stress: Direction for Research (eds E Light, BD Lebowitz): 340-62. Hemisphere Publishing

Mackenzie L, James I, Morse R, et al (2006) A pilot study on the use of dolls for people with dementia. Age and Ageing, 35: 441-4.

Mackenzie L, Wood-Mitchell A, James I (2007) Guidelines on using dolls. Journal of Dementia Care 15: 26

Marim C, Silva V, Taminato M, et al (2013) Effectiveness of educational programs on reducing the burden of caregivers of elderly individuals with dementia: a systematic review. Revista Latino-Americana de Enfermagem, 21: 267-75.
McKeown J, Clarke A, Repper J (2006) Life story work in health and social care: systematic literature review. Journal of Advanced Nursing, 55: $237-47$.

Meissen B (1993) Alzheimer's disease, the phenomenon of parent fixation and Bowlby's Attachment Theory. International Journal of Geriatric Psychiatry, 8: 147-53.

Moniz-Cook E, Swift K, James I, et al (2012) Functional analysis based interventions for challenging behaviour in dementia. Cochrane Database of Systematic Reviews, 2: CD006929.

Moos I, Bjorn A (2006) Use of the life story in the institutional care of people with dementia: a review of intervention studies. Ageing and Society, 26: 431-54

Morgan D, Stewart N, D'arcy K, et al (2004) Evaluating rural nursing home environments: dementia special care units versus integrated facilities. Aging and Mental Health, 8: 256-65.

National Collaborating Centre for Mental Health (2007) Dementia: A NICE-SCIE Guideline on Supporting People with Dementia and their Carers in Health and Social Care. British Psychological Society and Gaskell.

National Institute for Health and Clinical Excellence (2008) Physical Activity and the Environment (NICE Public Health Guidance 8). NICE.

Neal M, Barton Wright P (2003) Validation therapy for dementia. Cochrane Database of Systematic Reviews, 3: CD001394.

Neal M, Wright PB (2009) Validation therapy for dementia (update). Cochrane Database of Systematic Reviews, 1: CD001394.

Olazarán J1, Reisberg B, Clare L, et al (2010) Nonpharmacological therapies in Alzheimer's disease: a systematic review of efficacy. Dementia and Geriatric Cognitive Disorders, 30: 161-78.

Oyebode J, Clare L (2008) Supporting Cognitive Abilities. Excellence in Dementia Care: Principles and Practice. Open University Press

Parker C, Barnes S, McKee K, et al (2004) Quality of life and building design in residential and nursing homes for older people. Ageing and Society, 24: 941-62

Perrin T (1997) Occupational need in severe dementia: a descriptive study. Journal of Advanced Nursing, 25: 934-41.

Perrin T, May H (2000) Wellbeing and Dementia: An Occupational Approach for Therapists and Carers. Churchill Livingstone.

Rentz CA (2002) Memories in the making: outcome-based evaluation of an art program for individuals with dementing illnesses. American Journal of Alzheimer's Disease and Other Dementias, 17: 175-81.

Rieckmann N, Schwarzbach C, Nocon M, et al (2009) Pflegerische Versorgungskonzepte für Personen mit Demenzerkrankungen (HTABericht 80) [Concepts of Care for People with Dementia (HTA Report 80)]. Deutschen Institut für Medizinische Dokumentation und Information.

Robinson L, Clare, Evans K (2005) Making sense of dementia and adjusting to loss: psychological reactions to a diagnosis of dementia in couples. Ageing and Mental Health, 9: 337-47.

Sanchez A, Millan-Calenti J, Lorenzo-Lopez L, et al (2013) Multisensory stimulation for people with dementia: a review of the literature. American Journal of Alzheimer's Disease and Other Dementias, 28: 7-14.

Schwarzbach C, Förstl H, Nocon M, et al (2012) Why is it so difficult to evaluate nursing interventions in dementia? Dementia and Geriatric Cognitive Disorders Extra, 2: 146-59.

Spector A, Orrell M, Davies S, et al (2000) Reality Orientation for dementia: a review of the evidence of effectiveness from randomised controlled trials. Gerontologist, 40: 206-12.

Stevenson A, Thomson J, Roth H (2010) Dolls: handle with care. Journal of Dementia Care, 18: 16-7.

Thompson R (2011) Using life story work to enhance care. Nursing Older People, 23: 16-21.

Ueda T, Suzukamo Y, Sato M, et al (2013) Effects of music therapy on behavioral and psychological symptoms of dementia: a systematic review and meta-analysis. Ageing Research Reviews, 12: 628-41. 
Verity $\mathrm{J}$ (2006) Dolls in dementia care: bridging the divide. Journal of Dementia Care, 14: 25-7.

Vreugdenhil A, Cannell J, Davies A, et al (2012) A community-based exercise programme to improve functional ability in people with Alzheimer's disease: a randomized controlled trial. Scandinavian Journal of Caring Sciences, 26: 12-9.

Werezak L, Morgan D (2003) Creating a therapeutic psychosocial environment in dementia care. A preliminary framework. Journal of Gerontological Nursing, 29: 18.

Whitlatch CJ Feinberg L, Tucke S (2005) Measuring the values and preferences for everyday care of persons with cognitive impairment and their family caregivers. Gerontologist, 45: 370-80.
Winchester, J, Dick MB, Gillen D, et al (2012) Walking stabilizes cognitive functioning in Alzheimer's disease (AD) across one year. Archives of Gerontology and Geriatrics, 56: 96-103.

Woods R, Bruce E, Edwards R, et al (2012) REMCARE: reminiscence groups for people with dementia and their family caregivers effectiveness and cost-effectiveness pragmatic multicentre randomised trial. Health Technology Assessment, 16: v-xv, 1-116.

Zeisel J, Silverstein N, Hyde J, et al (2003) Environmental correlates to behavioral health outcomes in Alzheimer's special care units. Gerontologist, 43: 697-711.

Zeisel J (2009) I'm Still Here: A New Philosophy of Alzheimer's Care. Penguin Group.

\section{MCOs}

Select the single best option for each question stem

\section{Doll therapy:}

a is based on Piaget's developmental theory

$\mathrm{b}$ is a gender-specific intervention

c can reduce anxiety and increase activity levels

$d$ is a harmless approach that can be used with everyone

$\mathrm{e}$ is not an effective alternative to medication.

\section{Regarding reminiscence therapy and life} story work:

a the REMCARE trial showed modest benefits for most patients

b the REMCARE trial was neither positive or negative for caregivers

c the REMCARE trial was a cohort-based study

d life story work is based partly on the principles of reminiscence therapy

e McKeown et al's 2006 randomised controlled trial concluded there were 'far reaching' benefits.

\section{Which of these statements regarding} post-diagnostic support is false?

a research supports a structured approach to post-diagnostic support

b Whitlatch et al found that people in the early stages of dementia are often unaware of the diagnosis

c Robinson et al felt that support should be provided for the carer and the person with dementia together

d supporting carers at the start can prevent crises occurring

e the National Dementia Strategy states that everyone should have post-diagnostic support.

\section{With regard to light therapy:}

a studies suggest that the timing and intensity of the light therapy are crucial to its efficacy

b the internal biological clock is least sensitive to light

c Barrick et al showed that agitation was lower under high-intensity morning light therapy d Forbes et al looked at light therapy of various intensities and timings

e Burns et al showed that light therapy for 2 weeks at 10000 lux from $14.00 \mathrm{~h}$ to $16.00 \mathrm{~h}$ reduced agitation on the CMAI.

5 Regarding non-pharmacological interventions:

a they should be tried if medication is unsuccessful

b they are not effective as the evidence base is weak

c cognitive stimulation therapy is a useful intervention for everyone with dementia

$d$ they are a cheaper alternative to medication

e they should be about the general well-being of the person rather than just minimising BPSD. 